C2008 IEEE. Personal use of this material is permitted. However, permission to reprint/republish this material for advertising or promotional purposes or for creating new collective works for resale or redistribution to servers or lists, or to reuse any copyrighted component of this work in other works must be obtained from the IEEE. 


\title{
Governance for E-learning Ecosystem
}

\author{
Vanessa Chang $^{1}$ and Lorna Uden ${ }^{2}$ \\ ${ }^{1}$ School of Information Systems, Curtin University of Technology, Perth, Australia \\ e-mail: vanessa.chang@curtin.edu.au \\ ${ }^{2}$ Faculty of Computing, Engineering and Technology, Staffordshire University, Stafford, United Kingdom \\ email:1.uden@staffs.ac.uk
}

\begin{abstract}
Governance has emerged as an important issue for organisations across the world. Governance is the combined activities of developing and managing cohesive and consistent policies, processes and decisions right for a given area of responsibility. For an e-learning ecosystem to work effectively, it is essential that we have the right regulatory, technological and social conditions. This paper discusses a framework to support the successful implementation of an e-learning system includes (1) organisational decision making structures, (2) processes which include operational and technical supports, and (3) communications and relational mechanisms. Six characteristics and dimensions of Darking's [12] digital ecosystem governance were used to enhance the framework. E-learning information security governance is also discussed in the paper. The underlying goals for adopting e-learning governance practices are improvement of business performance and conformance to regulations. This paper discusses governance for elearning ecosystems within the digital business ecosystems (DBE).
\end{abstract}

Index Terms - governance, e-learning, e-learning ecosystem, e-learning governance, information security e-learning governance

\section{INTRODUCTION}

E-learning is crucial to the success of business if organisations want to remain competitive. The ultimate goal of elearning is to impart knowledge and skills that the business needs in a productive and cost-effective way. To develop effectual e-learning, organisations need guidance to improve their e-learning processes. A flexible process model independent of organisational structures, technical platforms, and pedagogical frameworks is required. To achieve this, organisations need to apply governance in order to be successful in e-learning. According to the COBIT Steering Committee [2], e-learning governance is defined as the responsibilities and practices carried out with a view to (i) provide strategic direction to an institution's e-learning initiatives, (ii) ensure that established objectives are achieved, (iii) manage risks properly, and (iv) allocate resources appropriately. To accomplish the above, e-learning governance applies control principles in the delivery of knowledge and skills that the business needs with direction, cost effectiveness, quality, ethics and security.

This paper begins with a brief review of e-learning, elearning ecosystems, the role of governance in DBE, fol- lowed by e-learning governance. Discussion on the importance of e-learning ecosystems and the need for e-learning governance framework of structures, processes, communications and relational mechanisms is also introduced in this paper. To enhance the e-learning governance framework of structures, processes, and communications and relational mechanisms, we have adopted the characteristics and dimensions of digital ecosystem governance of Darking [11]. In particular, information security governance is also described in detail. This paper concludes with discussion regarding further research in e-learning governance.

\section{E-LEARNING SYSTEM}

E-learning is a terminology that is synonymously associated with learning technology [10]. It is the use of networked information and communications technology (ICT) to extend, enhance and enrich learning activity. It can also be described as the acquisition of knowledge and skills through the processing of information within a context involving the construction and de-construction of meaning facilitated by ICT.

Despite the maturity of e-learning since its inception, many practitioners remain frustrated with the cost and complexity of integrating these systems with content and with other business systems. It seems these challenges detract businesses from a greater vision for online-learning [1]. Current e-learning systems pay little attention to issues of integrating learning with various systems, business processes and the contents where learning actually takes place. If elearning is to be effective in providing greater access to education and support educational programs that reflect broader strategic business goals, it is important that the elearning industry learns key lessons from its early business adopters.

\section{E-LEARNING ECOSYSTEMS}

An e-learning ecosystem is the learning community, together with the enterprise, united by a learning management system (LMS) [1]. A natural ecosystem is a biological community of interacting organisms and their physical environment [4]. Conversely, a business ecosystem is a network of buyers, suppliers and makers of related products or services and their socio-economic environment that includes institutional and regulatory framework. A digital 
ecosystem is a self-organising digital infrastructure aimed at creating a digital environment for networked organisations that supports the cooperation, the knowledge sharing, the development of open and adaptive technologies and evolutionary business models. Figure 1 shows a multi-layer of digital business ecosystem.

Moore first introduced the concept of a business ecosystem as a strategic plan [9]. Moore indicated that organisations form part of a business ecosystem and as such should be viewed as a collective rather than an individual entity. In a business ecosystem that crosses a variety of industries, organisations cooperate, compete, and co-evolve capabilities around a new innovation, support new products, satisfy customer needs, and eventually incorporate the next round of innovation.

According to Nachira [6], the key elements of a business ecosystem (top-most layer) include 1) governance, regulations and industrial policy, 2) human capital, knowledge and practices, 3) service and technical infrastructure, and 4) business and financial conditions.

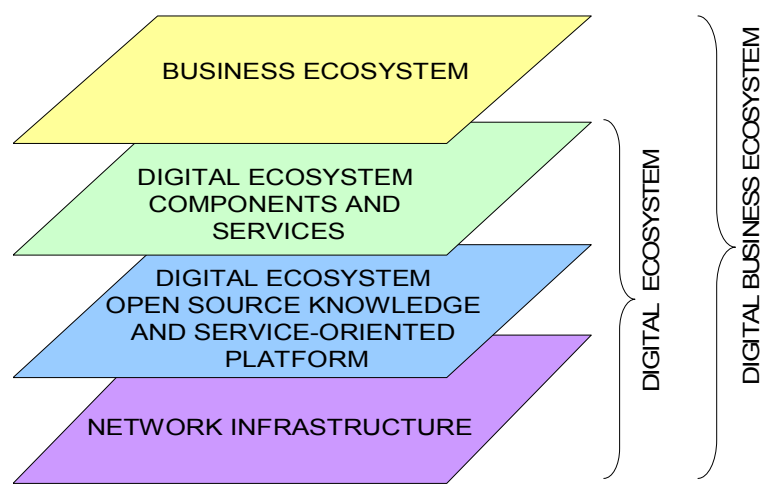

Fig. 1 Multi-layer digital business ecosystem (after F.Nachira [6])

According to Brodo [8], the term e-learning ecosystem is used to describe all the components required to implement an e-learning solution. These components, as shown in Figure 2, fall into three categories: content providers, consultants, and infrastructure.

Chang and Guetl [20] refined Brodo's components of elearning ecosystem by delineating a comprehensive building block required for e-learning development. The elements as shown in Figure 3 are (1) the learning communities and other stakeholders (referred to as biotic units) such as teachers, tutors, content providers, instructional designers and pedagogical experts (2) the learning utilities (referred to as abiotic units) or the learning environment includes the learning media (content and pedagogical aspects), technology, and tools applied in traditional teaching methods, (3) the learning environmental borders of physical and logical boundaries of the e-learning system, and (4) the learning ecosystem conditions of external and internal influences, such as evolution of knowledge, educational goals, learning tasks, cultural and sociological aspects, and expectations by society, private industry, profit and not-for-profit organisations, and the government.

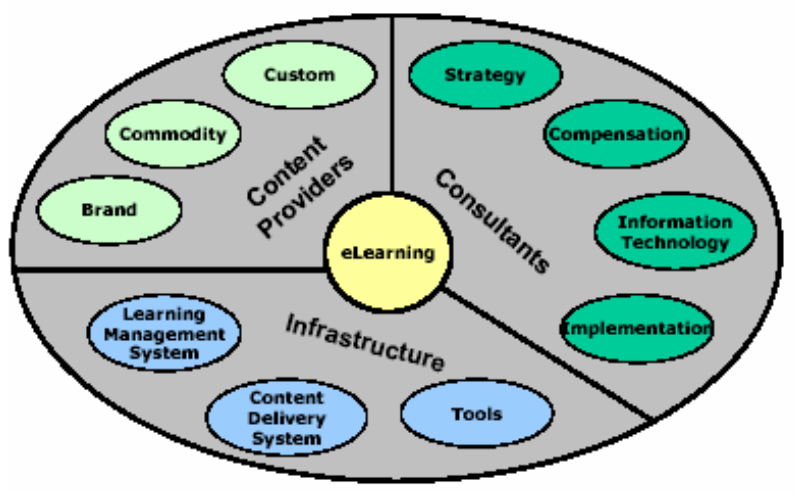

Fig.2 Brodo's e-learning ecosystem component

\section{A. Benefits of e-learning ecosystems}

E-learning ecosystems offer many benefits to organisations. In an organisation, a fully developed e-learning ecosystem can include a human-resource-integrated system such as a web-based portal where employees can check their benefits, make changes to medical plans and access learning programs that teach competencies that tie to business objectives and personal career aspirations. Training officers can access data that helps them integrate their programs to corporate goals, empower line managers to recommend and track training activity, and apply business discipline to help manage the learning assets and activity of the entire enterprise. Organizations with a systematic approach to rolling out these programs will ultimately benefit from a return on investment (ROI), increased productivity and improved employee performance [1].

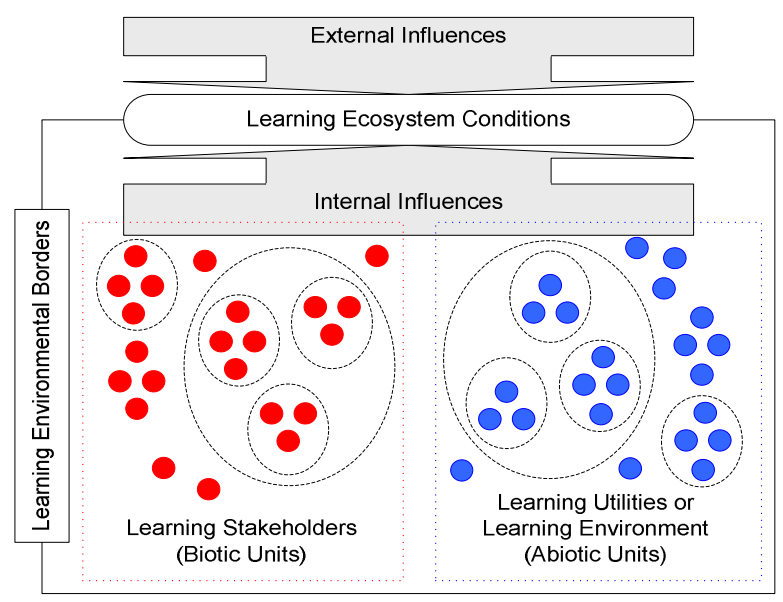

Fig.3 Simplified representation for the e-learning ecosystem 


\section{THE ROLE OF GOVERNANCE}

The term governance is often used to describe the relationship between a government and its people, or the relationship between a company and its shareholders. The latter is often referred to as corporate governance [16]. The role of governance encompasses characteristics that are also context specific. Governances such as IT governance, project governance, information security governance and e-learning governance are an integral part of corporate governance.

Darking [11] refers to governance as the constitution of relationships between different social groups and the processes of decision-making through which rights and responsibilities are established and defined. Governance is the process of decision-making and the process by which decisions are implemented (or not implemented). It can be used in several contexts such as corporate governance, international governance, national governance and local governance. More specifically and as discussed previously, governance may also include IT governance, project governance, information security governance and e-learning governance

As specified by Darking $[11,12]$, governance focuses attention on principles and dimensions that have a generic or universal quality, such as duties, rights and responsibilities. Mansell [13] states building governance can be understood to be comprised of a range of different practices and working rules. The rules and practices constitute a basis for coordination and an associated culture of meeting and communication $[11,12]$. Legally constituted entities and relationships bind and characterise relationship at the formal end of the spectrum. Informal environments afford flexibility and reduced organizational overhead and less reliance on formal contact.

\section{E-LEARNING GOVERNANCE}

According to Mansell [13], governance can comprised a range of different practices and working rules. Darking [11, 12] believes that it is important to consider the social, regulatory and technological aspects of ecosystem-based technologies and social networks in order to understand the role of governance in digital ecosystems. It is our belief that these considerations should also be applied to e-learning ecosystems. Besides this, we should also need to understand governance as a spectrum of working practices that include both formal and informal working arrangements. It is also important to use the latest development in technology infrastructure and design to create a framework for elearning ecosystem in order to enable users to cross the digital divide between organizations and regions. For this to happen we must have the right regulatory, social and technological conditions.

In the literature, very few governance papers or studies are reported for e-learning, however, the term IT governance is reported to have appeared in the research literature towards the late 1990s [7],[15],[16],[17]. De Haes and Van Grem- bergen $[17,18]$ and Peterson [15] propose that IT governance can be implemented through a framework of structures, processes, and relational mechanisms. The same set of framework may be applied to e-learning governance. Table 1 shows a brief summary of the key elements of (1) structures, (2) processes, and (3) communication and relational mechanisms for e-learning governance adapted from the work of De Haes and Grembergen [18] on IT governance. Structures include the existence of well defined roles and responsibilities and steering committees. Processes involve strategic planning and the use of various IT and e-learning governance standards which can provide the organisation with the means of examining its activities and its value to business. Communications and relational mechanisms include shared learning and strategic dialogue between business and IT.

Key Elements in the implementation of E-learning Governance

Structures:

Roles and responsibilities, organisation structure, Chief Learning Officer on board, Chief Information Officer, Estrategy committee, steering committee(s)

Processes:

Strategic planning, licensing and regulations, service level agreements, service and technical management, information security and risk management, infrastructure management system, software management, network management, resource management

Communications \& Relational mechanisms:

Active participation and collaboration between principle stakeholders, partnership rewards and incentives, Crossfunctional business communication

Table 1. E-learning governance framework: structures, process and relational mechanisms (after S. De Haes and W.Van Grembergen [18])

E-learning governance should focus on high level work to keep the organisation operating within legal and ethical bounds - the relevant acts and regulations governing elearning and organisations; partnerships and multilateral agreements to signatory, showing leadership in organisation as well as monitoring and reporting internally and externally on all aspects of operations. In addition, e-learning governance should also emphasize on the pedagogical and didactic aspects of learning, as well as focusing on the characteristics of cognitive learning. This considered, a new and fourth element for e-learning governance of 'Pedagogies and Instructional Designs' is added to the framework. Table 2 shows a revised list of elements for e-learning governance framework.

For an e-learning ecosystem to work effectively, it is necessary that we have a fitting framework as suggested in Table 2. Darking [12] insists that framework to develop e-learning must include regulatory, technological and social conditions. She expresses that regulatory, technological and or- 
ganisational cannot be studied in isolation from one another. Each of these constituents can alter the basis according to which interaction takes place. Alteration of one can have consequences for each of the others. It is therefore important to consider regulatory, organizational, technological and social dimensions both respectively and relative to one another in governance.

\begin{tabular}{|l|}
\hline Key Elements for E-learning Governance \\
\hline Structures: \\
Roles and responsibilities, organisation structure, Chief \\
Learning Officer on board, Chief Information Officer, E- \\
strategy committee, steering committee(s) \\
\hline Processes: \\
Strategic planning, licensing and regulations, service level \\
agreements, service and technical management, informa- \\
tion security and risk management, infrastructure man- \\
agement system, software management, network manage- \\
ment, resource management \\
Communications \& Relational Mechanisms: \\
Active participation and collaboration between principle \\
stakeholders, partnership rewards and incentives, cross- \\
functional business communication \\
\hline Pedagogies \& Instructional Designs: \\
Pedagogy strategies, instructional design standards, cogni- \\
tive learning strategies, learning styles
\end{tabular}

Table 2. Revised e-learning governance framework

\section{A. Characteristics and dimensions of e-learning govern- ance}

To enhance our e-learning governance framework of structure, processes and communications and relational mechanisms, we have adopted the dimensions of digital ecosystem governance of Darking [12]. It is our belief that these 6 characteristics and dimensions as presented in Table 3 are interrelated and at times overlapping. These dimensions also cut across the organisational, regulatory and technological framework.

The framework of structures, processes, and communications and relational mechanisms as presented in Table 1 and Darking's 6 characteristics and dimensions as shown in Table 3 underpin the adoption and implementation of elearning systems in organisations.

The purpose of identifying the framework and the characteristics and dimensions is to consider issues associated with digital ecosystems governance in particular for e-learning governance. The framework, characteristics and dimensions can be applied to tangible areas that arise as relevant to digital governance and coordination efforts [12]. From a research perspective, this could serve as a basis for formulating an approach for exploring, setting the boundaries and assessing the relevance of issues associated with e-learning ecosystems governance [12].

\section{INFORMATION SECURITY E-LEARNING GOVERNANCE}

One of the more important aspects of e-learning ecosystem governance is the information security governance. According to Kritzinger and von Solms [3], information security is important within the e-learning environment because e-learning is mainly dependent on information communication technologies (ICT). The use of ICT can lead to many security risks that can compromise information. It is therefore important to take steps to ensure that information is secured within the e-learning environment. Kritzinger and von Solms [3] propose four ways of helping institutions to secure their information against harmful attacks. These include:

- Ensuring e-learning information security governance.

- Creating e-learning information security policies and procedures.

- Implementation of e-learning information security counter-measures.

- Monitoring the e-learning information security counter-measures.

\begin{tabular}{|c|c|}
\hline $\begin{array}{l}\text { Characteristics of e-learning } \\
\text { ecosystem }\end{array}$ & $\begin{array}{l}\text { Dimensions of e- } \\
\text { learning ecosystem } \\
\text { governance }\end{array}$ \\
\hline $\begin{array}{l}\text { Shared values, common vision, } \\
\text { participation and membership } \\
\text { expressed in constitutional } \\
\text { documents such as bill of rights, } \\
\text { code of practice }\end{array}$ & $\begin{array}{l}\text { Constitution and } \\
\text { balance of interests }\end{array}$ \\
\hline $\begin{array}{l}\text { 2. Transparency inclusion, due } \\
\text { process, policy, procedure and } \\
\text { accountability }\end{array}$ & $\begin{array}{l}\text { Culture of communi- } \\
\text { cation }\end{array}$ \\
\hline $\begin{array}{l}\text { 3. Alliance forming and regional } \\
\text { coordination, allow for diverse } \\
\text { governance models and member- } \\
\text { ship }\end{array}$ & $\begin{array}{l}\text { Credibility, } \\
\text { attunement and trust }\end{array}$ \\
\hline $\begin{array}{l}\text { Distributed template, lightweight } \\
\text { organisation and synchronisation } \\
\text { for aligning code base infrastruc- } \\
\text { ture development; association } \\
\text { and alliance forming }\end{array}$ & $\begin{array}{l}\text { Organisation and } \\
\text { synchronisation }\end{array}$ \\
\hline $\begin{array}{l}\text { Knowledge and technology li- } \\
\text { censing, regulatory framework } \\
\text { for digital ecosystem e-learning } \\
\text { introduction and legal definitions } \\
\text { relevant to e-learning ecosystem } \\
\text { entry. } \\
\text { Choice of e-learning develop- } \\
\text { ment methodologies, technologi- } \\
\text { cal directions and infrastructure } \\
\text { standards and e-learning }\end{array}$ & $\begin{array}{l}\text { Licensing and } \\
\text { regulation }\end{array}$ \\
\hline $\begin{array}{l}\text { 6. Standards: associations and alli- } \\
\text { ance forming }\end{array}$ & $\begin{array}{l}\text { Technological } \\
\text { dimension }\end{array}$ \\
\hline
\end{tabular}

Table 3. Characteristics and dimensions of e-learning ecosystem governance (Darking [12]) 
Included in information security governance is risk management. To secure an e-learning system, it is necessary that we identify and assess possible risks. There should be some control and security measures to minimise it. Besides control, there should be some measures to enable us to determine if the process is functioning properly and whether it is likely to achieve its goals.

Another dimension of e-learning ecosystems is that of credibility, attunement and trust, as listed in Table 3. According to Nachira [5], the aim of digital business ecosystems is to overcome existing barriers and to promote innovative software creation, knowledge sharing, and community building in order to promote growth and competitiveness for SMEs in Europe. Digital business ecosystem is the new, faster and more flexible mode of cooperation and networking through the dynamic aggregation and selforganising evolution of organisations by means of an open source infrastructure. Because of the open source infrastructure of an e-learning ecosystem compared with proprietary e-learning software, version control cannot be tightly managed. This presents unique challenges that are difficult to manage. An open source model for e-learning ecosystem is a decentralised system, open to a diverse range of participants, access many locations, making control more difficult to achieve. The aim of achieving self-organising e-learning ecosystem suggests the need for a higher order capability to reproduce components with minimal intervention by human agents, making it a great challenge to control quality. An option suggested by Calderwood and Tsatsou [19] is the creation of a knowledge base for relevant generic regulatory issues. We concur with these authors that trust is essential to e-learning ecosystem activities. The regulatory domain is central to build trust relationships.

Mayer, et al [14] define trust as "the willingness of a party to be vulnerable to the actions of another party, based on the expectations that the other party will perform a particular action important to the trustee, irrespective of the ability to monitor or control that party". A degree of confidence or certainty is relevant to trust in the following three facets that Nachira [5] identifies as the necessary attributes of a digital ecosystem. These three types of trust are also essential for the e-learning ecosystem.

- Trust in service and technological solutions.

- Trust in business activities.

- Trust in knowledge.

Another important role of e-governance for e-learning ecosystem is that of a knowledge base. The building of a knowledge base of regulatory issues in an e-learning ecosystem is to draw on key regulatory issues. The issues identified as being important in the domains of regulatory environments when developing e-learning ecosystems are (1) privacy and consumer protection, (2) e-signature and security and (3) jurisdiction and consumer protection [19]. In addition to a knowledge base of regulatory issues, it is also important to have a taxonomy framework for the knowledge base of regulatory issues in e-learning ecosystems.

\section{CONCLUSIONS AND FUTURE WORK}

The paper highlighted some key issues in the context of adopting and implementing e-learning ecosystem governance within the digital business ecosystem. E-learning is a strategic advantage to organisations and governance is needed to ensure success in e-learning implementation. The authors identified an e-learning ecosystem governance framework of structures, processes, communications and relational mechanisms, and pedagogies and instructional designs. To further strengthen the framework, we have adopted the characteristics and dimensions of digital ecosystem governance of Darking [12]. The authors also provided a detailed overview of the importance of information security e-learning governance. Given that this is reasonably an unexplored area, further exploratory study needs to be carried to better understand the business benefits of improving e-learning governance practices in the evolving digital business ecosystem.

\section{REFERENCES}

[1] C.Price, E-learning Ecosystems: The Future of Learning Technology, 2004, Retrieved from 20 Aug 2007 from http://www.clomedia.com/content/templates/clo_feature_tech.asp?a rticleid $=618 \&$ zoneid $=72$.

[2] CoBIT Steering Committee and the IT Governance Institute, Information Systems Audit and Control Association, COBIT Management Guidelines, $3^{\text {rd }}$ Edition, July 2000.

[3] E.Kritzinger and S.H.von Solms, "E-learning: Incorporating Information Security Governance", Issues in Information Science and Information Technology, Informing Science Institute, Vol. 3, 2006.

[4] Encyclopaedia Britannica, Retrieved 20 Aug 2006 from http://www.britannica. com/eb/article-9031944 and http://www. answers.com/topic/ecosystem

[5] F.Nachira, Towards a Network of Digital Business Ecosystems fostering the local development, 2002, Retrieved on 16 Aug 2007 from http://www.digital-ecosystems.org.

[6] F.Nachira, "Innovation Ecosystems: Una Strategia europea per l'innovazione e lo sviluppo economico", 2005, Retrieved on 21 Aug 2006 from http://www.digital-ecosystems.org

[7] J.Bhattacharjya and V.Chang, The Role of IT Governance in the Evolution of Organizations in the Digital Economy: Cases in Australian Higher Education, Proceedings of the Inaugural IEEE International Conference on Digital Ecosystems and Technologies, Cairns, Australia, Feb, 2007.

[8] J.A.Brodo, Today's Ecosystem of e-learning, Retrieved on $21 \mathrm{Sep}$ 2006 from http://www.richardson.com/pdf/ecosystem.pdf.

[9] J.F.Moore, "Predators and Prey: A New Ecology of Competition," Harvard Business Review, May-June, 1993.

[10] L.Uden, "Introduction to Learning Technology". International Journal of Learning Technology, 1(1), pp 1-15, 2004. ISSN: 14778386, ISSN: 1741-8119.

[11] M.Darking, Digital Ecosystem Governance, Workshop Packages 32 Internal Report M32.4, prepared by London School of Economics, December 2006.

[12] M.Darking, Understanding the Role of Governance in the context of Digital Ecosystem", 2007, Retrieved on 16 Aug 2007 from http://www.digital-ecosystems.org/book/Section2.pdf.

[13] R.Mansell, "Collective action, institutionalism, and the internet" Journal of Economic Issues, 40(2), pp.297-305, 2006.

[14] R-C.Mayer, J.H. Davis and F.D. Schoorman, "An integrated model of organisational trust". Academy of Management Review, 20, pp 709-734, 1995.

[15] R.Peterson, "Crafting Information Technology governance”, Information Systems Management, 21, 4, pp. 7-22, 2004.

[16] S.Benn and D.Durphy, Corporate governance and sustainability. challenges for theory and practice, Routledge, New York, 2006. 
[17] S.De Haes and W.Van Grembergen, "IT Governance and its Mechanisms," Information Systems Control Journal, 1, 2004.

[18] S. De Haes and W.Van Grembergen, "IT Governance Structures, Processes and Relational Mechanisms: Achieving IT/Business Alignment in a Major Belgian Financial Group" in Proceedings of the $38^{\text {th }}$ Hawaii International Conference on System Sciences, 2005.

[19] S.E.Calderwood and P.Tsatsou, "Trust among SMEs in Digital Business Ecosystems: Theoretical and methodological foundations for establishing trust through knowledge base of regulatory issues" In F. Nachira, A. Nicolai, P. Dini, M. Le Louarn, and L.R. Leon (eds), Digital Business Ecosystems, European Commission Information Society and Media, pp 98-105, 2007.

[20] V.Chang and C.Guetl, E-Learning Ecosystem (ELES) - A Holistic Approach for the Development of more Effective Learning Environment for Small-and-Medium Sized Enterprises (SMEs), Proceedings of the Inaugural IEEE International Conference on Digital Ecosystems and Technologies, Cairns, Australia, Feb, 2007. 